\title{
Solid state chemistry of Ruddlesden-Popper type complex oxides
}

\author{
INDU BHUSHAN SHARMA* and DEVINDER SINGH \\ Department of Chemistry, University of Jammu, Jammu 180006 , India \\ MS received 16 September 1997; revised 27 April 1998
}

\begin{abstract}
Various criteria of formation of perovskites and $\mathrm{K}_{2} \mathrm{NiF}_{4}$-type compounds, which are the end members of homologous Ruddlesden-Popper series of phases, have been discussed. RP-phases show some general trends in their physical properties. Literature survey of the formation of these phases, their properties, and effect of oxygen stoichiometry and doping is presented. Some conditions for their synthesis are also described.
\end{abstract}

Keywords. RP-type complex oxides; synthesis; crystal structure; physical properties.

\section{Introduction}

Complex oxides of composition $\mathrm{ABO}_{3}$ generally take up perovskite structure provided a tolerance factor $(t)$, which is defined by the relation $t=\left(r_{\mathrm{A}}+r_{\mathrm{O}}\right) / \sqrt{2}\left(r_{\mathrm{B}}+r_{\mathrm{O}}\right)$, has value between 0.75 and 1 , where $r s$ are the ionic radii (Geller and Wood 1956; Katz and Ward 1964; Glasso 1969; Ganguly and Rao 1984; Rao and Gopalakrishnan 1986). Another study shows that perovskite and related compounds usually crystallize if $1.0<r_{\mathrm{A}}<1.9 \AA$ and $0.5<r_{\mathrm{B}}<1.2 \AA$ (Kafalas and Longo 1972). The complex oxides of general formula $\mathrm{A}_{2} \mathrm{BO}_{4}$ crystallize in $\mathrm{K}_{2} \mathrm{NiF}_{4}$ type structure, which could be said as consisting of perovskite slabs of unit thickness stacked one over the other along the $c$-axis such that adjacent slabs are displaced relative to one another by $1 / 21 / 21 / 2$ (Wells 1978). Crystal chemical considerations suggest that for $\mathrm{K}_{2} \mathrm{NiF}_{4}$-type structure to be stable, $r_{\mathrm{A}} / r_{\mathrm{B}}$ ratio should lie between 1.7 and 2.4 (Ganguli 1979; Rao et al 1984). According to the literature survey, of all the known compounds, hardly $5 \%$ have $r_{\mathrm{A}} / r_{\mathrm{B}}$ values lying outside the prescribed range. By using invariant method, Poix (1980) has given the following relation between the average cation-oxygen distances associated to the 9 and 6 coordinated sites $\left(\psi_{\mathrm{A}}\right.$ and $\left.\beta_{\mathrm{B}}\right)$ and volume $V$ of the unit cell in $\mathrm{K}_{2} \mathrm{NiF}_{4}$ structure:

$$
0.99615 V^{1 / 3}=\beta_{\mathrm{B}}+\psi_{\mathrm{A}} 2^{1 / 2} .
$$

$\mathrm{K}_{2} \mathrm{NiF}_{4}$-type structure is two-dimensional in the sense that only equatorial anions of $\mathrm{BO}_{6}$ octahedra are linked through the corners. The perovskite and $\mathrm{K}_{2} \mathrm{NiF}_{4}$-type structures are shown in figure 1. Recently, on the basis of a geometrical matching between the bond distances, a new tolerance factor, $t_{\mathrm{f}}=\left[3 \sqrt{2} r_{\mathrm{O}}+2 \sqrt{6}\left(r_{\mathrm{A}}+r_{\mathrm{O}}\right)\right] / 9\left(r_{\mathrm{B}}+\right.$

*Author for correspondence
$r_{\mathrm{O}}$ ), has been formulated for the $\mathrm{Nd}_{2} \mathrm{CuO}_{4}$-type structure, where $r_{\mathrm{A}}, r_{\mathrm{B}}$ and $r_{\mathrm{O}}$ are the radii of the $\mathrm{A}, \mathrm{B}$ and $\mathrm{O}$ ions, respectively (Chen 1996). $T^{\prime}$ phases occur for $t_{\mathrm{f}}<1.00$, while $T$ phases form for $t_{\mathrm{f}}>1.00$. The $T^{*}$ phase exists in a very narrow region between the stability boundaries of the other two structure-types.

The perovskites and $\mathrm{K}_{2} \mathrm{NiF}_{4}$-type compounds are the end members of homologous series of the phases given by the general formula $A_{n+1} B_{n} O_{3 n+1}$. This formula could also be written as $\mathrm{AO}\left(\mathrm{ABO}_{3}\right)_{n}$, where $n$ perovskite layers are stacked between rock-salt AO layers along the crystallographic $c$-axis (Ruddlesden and Popper 1957, 1958). Such compounds, also known as Ruddlesden-Popper (RP) type phases, exhibit interesting physical properties as one moves to higher members of the family. The three-dimensional character increases in higher members of the family because of presence of increased numbers of the $\mathrm{ABO}_{3}$ slabs. A schematic presentation of RP-type phases is given in figure 2 . In these structures, the $\mathrm{BO}_{6}$ octahedral corners share each other, extending infinitely in the $a b$ plane, and the $n$ units of such planes stack in the $c$-direction to form the perovskite slab. In case $\mathrm{A}$ is a rare earth and/or alkaline earth ion, and $\mathrm{B}$ is a transition metal ion in such compounds, the electric transport and magnetic properties of these phases within a given series are governed by the identity and valence state of the ions, width of $n$ perovskite slabs, B-O-B bond angle and the oxygen content (Singh et al 1984; Buttrey et al 1986; Zhang and Greenblatt 1994).

\section{General trends in properties}

It is interesting to note that in many RP-type compounds, magnetic properties reflect itinerant electron behaviour, while the electric transport properties do not; although both insulating and metallic behaviour are observed, the 
former is predominant. The lowest electric resistivity observed in an $n=1$ phase of any RP family is of the order of $10^{-2} \mathrm{ohm} \mathrm{cm}$. Resistivity generally decreases further in higher members of the family because of the increasing three-dimensional character (Rao et al 1988). $\mathrm{Sr}_{2} \mathrm{FeO}_{4}$ has resistivity of several orders of magnitude higher than the corresponding $n=2$ member (Adler 1994). In the $\mathrm{La}_{n+1} \mathrm{Ni}_{n} \mathrm{O}_{3 n+1}$ family, the room temperature resistivity $\left(\rho_{300}\right)$ decreases from $\sim 250 \mathrm{~m} \mathrm{ohm} \mathrm{cm}$ for the $n=2$ member to $\sim 1.8 \mathrm{~m}$ ohm $\mathrm{cm}$ for the $n=\infty$ member (Sreedhar et al 1994). The $\mathrm{K}_{2} \mathrm{NiF}_{4}$-type oxides, if metallic, do not show metallic phenomenon over wide range of temperature. However, higher members of the analogous series could be exception; $\mathrm{Sr}_{2} \mathrm{VO}_{4}$ is an insulator, while

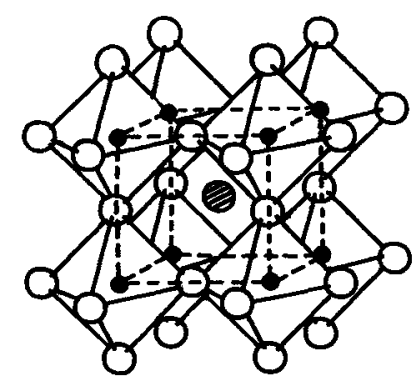

(a)

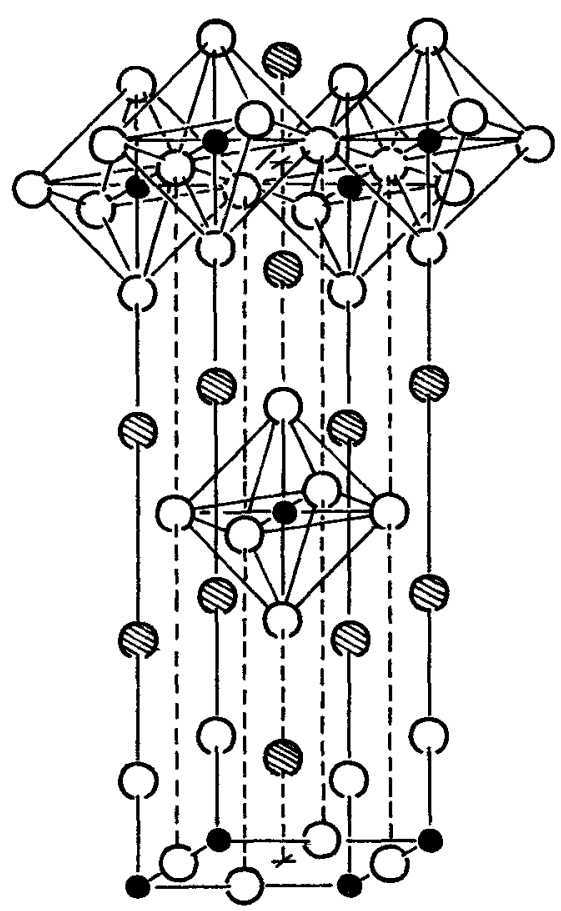

(b)

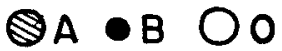

Figure 1. (a) Perovskite structure: and (b) $\mathrm{K}_{2} \mathrm{NiF}_{4}$ structure.
$\mathrm{Sr}_{4} \mathrm{~V}_{3} \mathrm{O}_{9.7}$ is metallic down to $4.2 \mathrm{~K}$ (Rey et al 1990; Gong et al 1991; Takeno et al 1991; Ohashi et al 1992). Moving upwards from $n=1$ to higher members of the family, an evolution in metallic conductivity is observed.

$\mathrm{K}_{2} \mathrm{NiF}_{4}$, which is paradigm of the $\mathrm{RP}$ phases when $n=1$, has magnetic cell with dimensions $a_{\mathrm{M}}=\sqrt{2} a_{\mathrm{CM}}$ and $c_{\mathrm{M}}=c_{\mathrm{CM}}$, where subscripts refer to magnetic (M) and chemical (CM) cells (Greedan et al 1992). The magnetic interactions are essentially antiferromagnetic; intralayer magnetic interactions are strongly antiferromagnetic due to nearest neighbour $180^{\circ} \mathrm{Ni}-\mathrm{F}-\mathrm{Ni}$ superexchange, while interlayer interactions are much weaker as the pathways, $\mathrm{Ni}-\mathrm{F}-\mathrm{K}-\mathrm{F}-\mathrm{Ni}$, are more convoluted. Stoichiometric twodimensional phases, having either $\mathrm{K}_{2} \mathrm{NiF}_{4}$ type structure or the one derived from the tetragonal $\mathrm{K}_{2} \mathrm{NiF}_{4}$ cell by an orthorhombic distortion, possess essentially the same magnetic structure as $\mathrm{K}_{2} \mathrm{NiF}_{4}$ except that moment direction may be along a different axes. Only a few compounds are known, namely, $\mathrm{LaSrFeO}_{4}$ and $\beta-\mathrm{Sr}_{2} \mathrm{MnO}_{4}$, which require a magnetic cell different from that of $\mathrm{K}_{2} \mathrm{NiF}_{4}$ $\left(a_{\mathrm{M}}=a_{\mathrm{CM}}\right)$ (Soubeyroux et al 1980; Bouloux et al 1981).

Flem et al (1982) have shown that it is possible to predict the electronic configuration of various cations in

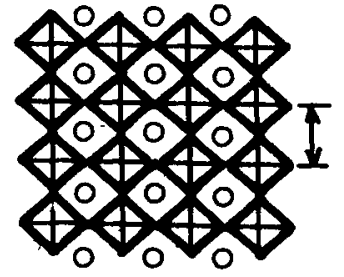

$\mathrm{ABO}_{3}$

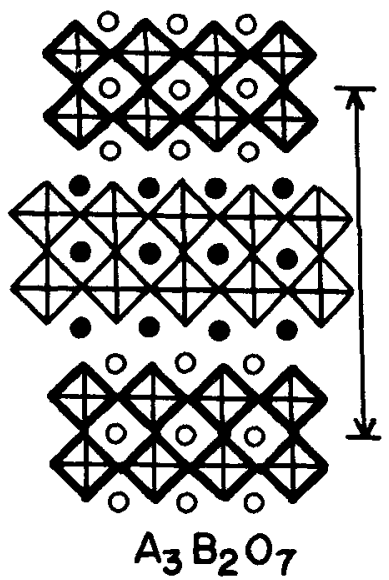

$\mathrm{A}_{3} \mathrm{~B}_{2} \mathrm{O}_{7}$

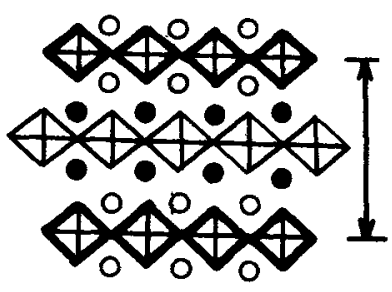

$\mathrm{A}_{2} \mathrm{BO}_{4}$

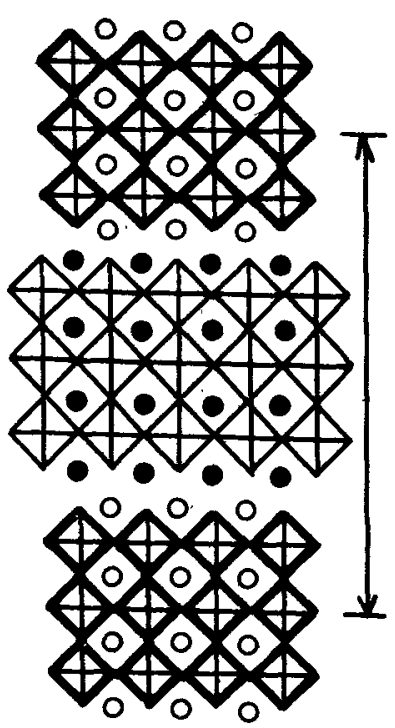

$\mathrm{A}_{4} \mathrm{~B}_{3} \mathrm{O}_{10}$
Figure 2. Schematic illustration of the members of $\mathrm{A}_{n+1} \mathrm{~B}_{n} \mathrm{O}_{3 n+1}$ series. 
$\mathrm{K}_{2} \mathrm{NiF}_{4}$-type oxides on the basis of elementary structural and boundary considerations. $\mathrm{CaLaFeO}_{4}$ and $\mathrm{SrLaFeO}_{4}$ ferrites have a prevailing 2D behaviour, while for $\mathrm{La}_{2} \mathrm{MnO}_{4}$ and $\mathrm{CaYCrO}_{4}$, in the absence of $e_{\mathrm{g}}$ electrons and $e_{\mathrm{g}}-p_{a}-e_{\mathrm{g}}$ bonds, the competition between $\pi(\mathrm{Mn}$, $\mathrm{Cr})-\mathrm{O}$ and $(\mathrm{Ca}, \mathrm{Ln})-\mathrm{O}$ bonds alters the $2 \mathrm{D}$ character of magnetic interactions and leads to 3D behaviour. Such deviations could be as a result of two factors: (i) decreasing distance between the magnetic $\left(\mathrm{MnO}_{4}\right)_{n}$ or $\left(\mathrm{CrO}_{4}\right)_{n}$ layers due to substitution of one ion by a smaller one in the 9-coordinated site, and (ii) decreasing the covalent character of $\mathrm{Mn}-\mathrm{O}$ or $\mathrm{Cr}-\mathrm{O}$ bonds.

Nature and size of the cations at the sites A and B influence the structure and properties of these layerstructured phases significantly. The size of A-site ion at the 9-coordinated position affects the cell parameters and consequently, the structure of these compounds. The larger cations at site A elongate the interlayer distance, hence increase in $c$, while smaller ions shorten it. The size of the ion at site $A$ is expected to affect the lattice constant $c$ more prominently than $a$. In the system $\mathrm{Ln}_{2} \mathrm{SrFe}_{2} \mathrm{O}_{7}$ ( $\mathrm{Ln}=\mathrm{La}, \mathrm{Nd}, \mathrm{Gd}$ and Dy), there is drastic change in $c$ as a result of the heavier rare-earth ions substitution, and in these quasi two-dimensional phases interlayer magnetic interactions become more dominant with decrease in $c$ (Sharma et al 1998). Because B-O interactions occur only along $a b$ plane, the cation at site $\mathrm{B}$ is expected to influence the cell parameter $a$ more predominantly.

Acidity of the ions at the $A$ and $B$ sites influences the structure and property. According to Goodenough (1971), more basic the cation at the position A higher is the covalency of the $\pi(\mathrm{B}-\mathrm{O})$ bond which competes with the $\sigma(\mathrm{A}-\mathrm{O})$ bond. The metallic character of $\mathrm{LaSrNiO}_{4}$ is due to strong covalency of the $\mathrm{Ni}-\mathrm{O}$ bonding. Another factor which influences the behaviour of these phases is the John-Teller effect, which comes into existence due to difference in the electronic population in the $e_{\mathrm{g}}$ orbitals. For example, high spin $\mathrm{Fe}^{4+}$ ion in $t_{2 \mathrm{~g}}^{4} e_{\mathrm{y}}^{4}$ electronic state undergoes John-Teller distortion due to anisotropic electronic configuration, affecting both structure and properties (Tresse et al 1993).

\subsection{Importance}

The intergrowth structures based on perovskite blocks in inorganic systems have provided a fertile field of solid state chemical research for many years for the rich variety of their structural and physical properties. The epoch making discovery of superconductivity in the $\mathrm{La}_{2-x} \mathrm{Ba}_{x} \mathrm{CuO}_{4}$ system, derived from $\mathrm{La}_{2} \mathrm{CuO}_{4}$, has added additional dimension to the investigation of these phases (Bednorz and Muller 1986; Cava et al 1987; Mohan Ram et al 1987). However, there has been much interest in the physical properties and structural chemistry of perovskite-related compounds even before the discovery of superconductivity for their wide range of applications such as ideal semiconductors, magnetic materials, high temperature superconductors, catalysts, electrode materials etc (Longo and McCauley 1986).

\subsection{Range of studies}

One of the extensively studied systems in RP series of phases is rare-earth copper oxides $\left(\mathrm{RE}_{2} \mathrm{CuO}_{4}\right)$. The rareearth copper oxides are known to exist in five different structural modifications, $T^{\prime}, T^{*}, T^{\prime \prime}$, and tetragonal and orthorhombic $T$ structures (Manthiram and Goodenough 1990; Chen and Eichhorn 1992). The specific structural modifications correlate exceedingly well with the value of the tolerance factor $t$. When a reasonable match between the $\mathrm{A}-\mathrm{O}$ and $\mathrm{B}-\mathrm{O}$ layers exists $(0.99 \geq t \geq$ 0.88 ), the $T$ phase is tetragonal with $I 4 / \mathrm{mmm}$ crystal symmetry. The tolerance factor in the range $0.88 \geq t \geq 0.87$ leads to orthorhombic distortion, while $t \leq 0.865$ results into $T^{\prime}$ (or $T^{*}$ ) structure. $\mathrm{La}_{2} \mathrm{CuO}_{4}$ crystallizes in a slightly distorted $\mathrm{K}_{2} \mathrm{NiF}_{4} T$-tetragonal structure at high temperature and undergoes a displacive transition to orthorhombic symmetry below transition temperature. Unlike $\mathrm{La}_{2} \mathrm{CuO}_{4}, \mathrm{Nd}_{2} \mathrm{CuO}_{4}$ has a $T^{\prime}$-tetragonal structure, consisting of planer $\left(\mathrm{CuO}_{2}\right)^{2}$ anionic layers cross linked by $\left(\mathrm{Nd}_{2} \mathrm{O}_{2}\right)^{2}$ layers. The A-site atoms are 8 -coordinated in this case against 9-coordinated in the $\mathrm{K}_{2} \mathrm{NiF}_{4}$ structure. The mixed lanthanide system $\mathrm{La}_{2-x} \mathrm{Ln}_{x} \mathrm{CuO}_{4}\left(\mathrm{Ln}=\mathrm{Sm}\right.$, Dy), takes up hybrid $T^{*}$ tetragonal structure. Here the inactive Ln-O layers alternate between the $(001)$ rocksalt $\mathrm{LaO}$ layers of the $T$ structure and the fluorite-type layers of the $T^{\prime}$ structure. The $T^{\prime \prime}$ structure suggests cation ordering within a Ln-O layer. The $T, T^{\prime}$ and $T^{*}$ structures are shown in figure 3 (James et al 1989; Tokura et al 1989; Bringley et al 1990).

The properties of $\mathrm{La}_{2} \mathrm{CuO}_{4+\delta}$ are extremely sensitive to change in oxygen stoichiometry. For a slightly negative value of $\delta, \mathrm{La}_{2} \mathrm{CuO}_{4+\delta}$ is an antiferromagnetic semi-

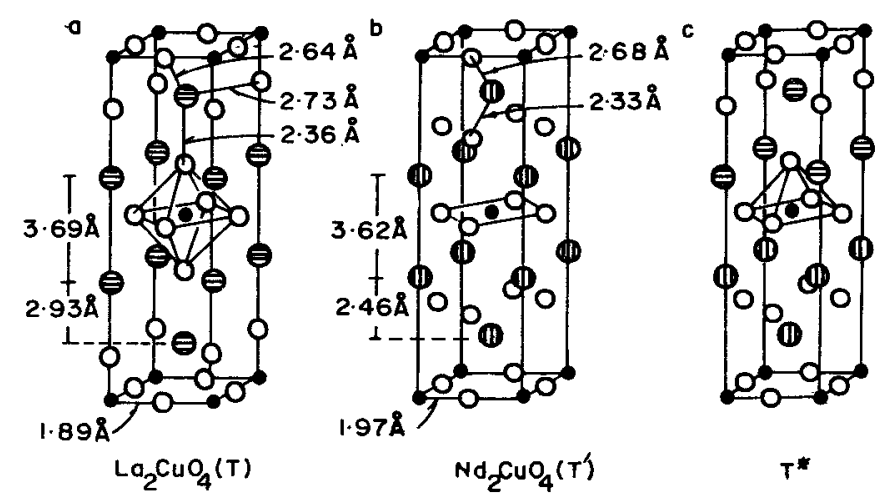

Figure 3. Illustration of the $T, T^{\prime}$ and $T^{*}$ structures. 
conductor. Antiferromagnetism disappears with change in oxygen stoichiometry as small as $1 \%$. As $\delta$ become positive, holes are introduced into the structure and metallic behaviour is observed (Bringley et al 1990). $\mathrm{La}_{2} \mathrm{CuO}_{4}$ when doped with holes either by introducing excess oxygen into the structure or partial replacement of $\mathrm{La}$ by alkaline earth metal ions, containing $\mathrm{Cu}$ nominally in mixed valent state $(2+, 3+)$, shows superconductivity (Cava et al 1987; Mohan Ram et al 1987). The compounds with $T$ structure become superconducting only when electron doped, which is possible by partial substitution of $\mathrm{Ce}$ at $\mathrm{RE}$-site or partial replacement of oxygen by fluorine. $\mathrm{Nd}_{1.85} \mathrm{Ce}_{(2) 15} \mathrm{CuO}_{4}\left(T_{\mathrm{c}}=24 \mathrm{~K}\right)$ and $\mathrm{Nd}_{2} \mathrm{CuO}_{3.6} \mathrm{~F}_{0.4}\left(T_{\mathrm{c}}=27 \mathrm{~K}\right)$ are examples of this category of superconductors (James et al 1989; Tokura et al 1989).

$\mathrm{La}_{n+1} \mathrm{Ni}_{n} \mathrm{O}_{3 n+1}(n=1,2$ and 3$)$ series is one of the widely studied systems (Poix 1980; Drenan et al 1982; Mohan Ram et al 1986; Bassat et al 1987; Buttrey and Honig 1988; Arbuckle et al 1990; Nanjundaswamy et al 1990; Sreedhar and Honig 1994; Sreedhar et al 1994; Zhang and Greenblatt 1994; Zhang et al 1994). The crystal structure of $\mathrm{La}_{2} \mathrm{NiO}_{4}$ is reported to be tetragonal with space group $14 / \mathrm{mmm}$; electron diffraction studies, however, show it having monoclinic distortion. The unit cells of $\mathrm{La}_{3} \mathrm{Ni}_{2} \mathrm{O}_{7}$ and $\mathrm{La}_{4} \mathrm{Ni}_{3} \mathrm{O}_{10}$ are orthorhombic; the former in the space group Fmmm. Electric transport and magnetic properties suggest an interesting 3-dimensional character across the homologous series with increase in $n$, and this trend is suggested to be related to the percolation threshold. $\mathrm{La}_{2} \mathrm{NiO}_{4}$ exhibits a semiconductormetal transition at around $550 \mathrm{~K}$, while $\mathrm{La}_{2-x} \mathrm{Sr}_{x} \mathrm{NiO}_{4}$ is reported to be superconducting down to $70 \mathrm{~K}$ (Kakol et al 1989; Rao et al 1989). Samples of $\mathrm{La}_{2} \mathrm{NiO}_{4}$, annealed in $\mathrm{CO}_{2}$ at $1400 \mathrm{~K}$, show evidence for long range antiferromagnetic ordering. The magnetic susceptibility seems to be simply the sum of the susceptibilities of $(n-1) \mathrm{LaNiO}_{3}$ and $\mathrm{La}_{2} \mathrm{NiO}_{4}$, as if $\mathrm{Ni}^{3+}$ and $\mathrm{Ni}^{2+}$ are segregated in different layers (Mohan Ram et al 1986). Results of another study suggest cross over from fluctuating valence to a Fermi-liquid-like behaviour with increase in $n$ (Bassat et al 1987). Fully reduced $\mathrm{La}_{3} \mathrm{Ni}_{2} \mathrm{O}_{6,35}$ shows linear dependence of $\operatorname{Ln} \rho$ vs $T^{-1 / 4}$, suggesting a variable range hopping mechanism for electrical conductance (Zhang et al 1994). Discovery of diamagnetism in $\mathrm{La}_{2} \mathrm{NiO}_{4+\delta}$ and $\mathrm{La}_{2-x} \mathrm{M}_{x} \mathrm{NiO}_{4}(\mathrm{M}=\mathrm{Ca}, \mathrm{Sr})$ compounds at low temperature is another reason for extensive studies on structure and properties of nickelates (Sreedhar and Honig 1994). In the series $\mathrm{La}_{n+1} \mathrm{CO}_{n} \mathrm{O}_{3 n+1}$, the $n=1$ and 3 phases are reported to crystallize in orthorhombic unit cell in the space group $F \mathrm{mmm}$ (Seppanen and Tikkannen 1976; Janecek and Wirtz 1978; Lehmann and Buschbaum 1980; Longo and McCauley 1986; Sharma and Singh 1995a). Some studies, however, suggest pseudo monoclinic/tetragonal structure for the $n=1$ phase (Lehuede and Daire 1973; Kniga et al 1979).
The $n=1$ and 2 phases in the series $\mathrm{Sr}_{n+1} \mathrm{Fe}_{n} \mathrm{O}_{3 n+1}$, $\mathrm{Sr}_{2} \mathrm{FeO}_{4}$ and $\mathrm{Sr}_{3} \mathrm{Fe}_{2} \mathrm{O}_{7}$, are reported to crystallize in the tetragonal unit cell in the space group $14 / \mathrm{mmm}$ on the basis of X-ray and neutron diffraction (Dann et al 1992; Adler 1994). The $n=1$ phase is Mott-type antiferromagnetic semiconductor undergoing magnetic ordering at about $60 \mathrm{~K} . \mathrm{LaSr}_{3} \mathrm{Fe}_{3} \mathrm{O}_{10-\delta}$, its mixed $\mathrm{Fe} / \mathrm{Al}$ analogue and the $\mathrm{Sr}_{n+1} \mathrm{Fe}_{n} \mathrm{O}_{3 n+1}(n=1$ and 3) phases are known to be iso-structural with the $\mathrm{Sr}_{n+1} \mathrm{Ti}_{n} \mathrm{O}_{3 n+1}$ compounds (Ruddlesden and Popper 1957, 1958; Lees et al 1993). $\mathrm{Ca}_{n+1} \mathrm{Ti}_{n} \mathrm{O}_{3 n+1-\delta}(n=2$ and 3$)$ phases show electrical conduction which has little dependence on the stacking number of perovskite slabs $(n)$, a phenomenon contrary to the belief that the properties of RP-phases are a function of $n$ (Kim et al 1992).

If the size of cation at site $A$ is too large relative to that at site $\mathrm{B}$, the $\mathrm{ABO}_{3}$ end members do not take up the perovskite or related structures at atmospheric pressure but form a hexagonal polytype, and to transform them to perovskite related structure higher pressures are needed. The phases of the systems $\mathrm{Sr}_{n+1} \operatorname{Ir}_{n} \mathrm{O}_{3 n+1}(n=1,2$ and 3) and $\mathrm{Sr}_{n+1} \mathrm{Cr}_{n} \mathrm{O}_{3 n+1}(n=1$ and 2$)$ have been synthesized by this process (Kafalas and Longo 1972). All the phases are known to have tetragonal unit cell dimensions. The synthesis under high pressure is achieved at faster pace.

The $n=1,2$ and 3 members in the series $\mathrm{Sr}_{n+1} \mathrm{~V}_{n} \mathrm{O}_{3 n+1}$ are reported to crystallize in tetragonal unit cell in the space group I4/mmm (Feltz and Schmalfuss 1975; Cryot et al 1990; Itoh et al 1990; Rey et al 1990; Gong et al 1991; Suzuki et al 1991; Takeno et al 1991; Ohashi et al 1992). The $n=2$ and 3 compounds exhibit metallic behaviour, while the $n=1$ compound is an antiferromagnetic insulator. The electric and magnetic properties of these compounds indicate that localized $t_{2 \mathrm{~g}}$ orbitals of $\mathrm{V}^{4+}$ ions transform into the collective narrow $\pi *$ bands with increasing number of perovskite layers $n$.

A possible correlation exists between the observed electrical properties and the degree of distortion in the $\mathrm{V}-\mathrm{O}$ polyhedra of $\mathrm{Sr}_{4} \mathrm{~V}_{3} \mathrm{O}_{10-\delta}$ (Takeno et al 1991; Ohashi et al 1992). This compound exists in two different polytypes. It is considered that because of their similarity of structural and physical properties with $\mathrm{La}-\mathrm{Cu}-\mathrm{O}$ superconductors, $\mathrm{Sr}_{n+1} \mathrm{~V}_{n} \mathrm{O}_{3 n+1}(n=1,2$ and 3) phases with $1 / 2$ spin of $\mathrm{V}^{4+}$ ion- the property considered essential for high $T_{\mathrm{c}}$ superconductivity in the $\mathrm{Cu}$-oxides-are the candidates for high $T_{\mathrm{c}}$ superconductivity with appropriate doping, although no such phase has as yet been discovered (Rey et al 1990; Gong et al 1991; Takeno et al 1991; Ohashi et al 1992).

$\mathrm{La}_{2} \mathrm{CuO}_{4}$ exhibits field-dependent ferromagnetism below $850 \mathrm{~K}$ and has nearly temperature-independent resistivity above $200 \mathrm{~K}$ except for small maximum near $530 \mathrm{~K}$ that is associated with a smooth $\mathrm{O}-\mathrm{T}$ transition (Singh et al 1984), while its alkaline earth- and alkali-substituted analogues are superconductors (Bednorz and Muller 1986; 
Mohan Ram et al 1987; Gunther and Schollhorn 1992). $\mathrm{La}_{2-x} \mathrm{Sr}_{x} \mathrm{CaCu}_{2} \mathrm{O}_{6+\delta}(212)$ and the related calcium doped compounds have been of considerable interest due to the discovery of superconducting behaviour in $\mathrm{La}_{2-x} \mathrm{Sr}_{x} \mathrm{CaCu}_{2} \mathrm{O}_{6+\delta}$ (Dann et al 1992).

In the system $\mathrm{Sr}_{n+1} \mathrm{Ru}_{n} \mathrm{O}_{3 n+1}(n=1$ and 2$)$, both the known phases crystallize with tetragonal unit cell in the space group I4/mmm (Muller-Buschbaum and Wilkens 1990; Huang et al 1994). When $n=1$ and 2, the phases are antiferromagnetic, while the $n=\infty$ phase is ferromagnetic conductor. Williams et al (1991) have shown that $n=2$ phase is metallic down to $4 \mathrm{~K}$, while we found that this phase follows variables range hopping mechanism in electric transport but the characteristic energy of hopping is much reduced (Sharma and Singh 1996). The recent discovery of superconductivity $\left(T_{c} \sim 1 \mathrm{~K}\right)$ in $\mathrm{Sr}_{2} \mathrm{RuO}_{4}$ has generated new interest in the ruthenates (Maeno et al 1994). Strontium ruthenates $\mathrm{SrRuO}_{3}$ and $\mathrm{Sr}_{2} \mathrm{RuO}_{4}$, while well known materials for some time, have been subject of renewed interest due to their low metallic resistivities and chemical compatibility with $\mathrm{YBa}_{2} \mathrm{Cu}_{3} \mathrm{O}_{7}$, suggesting that they might be useful as normal metal electrodes in superconducting thin film devices (Lichtenberg 1992; Cava et al 1995). The solidsolution $\mathrm{Sr}_{3 x} \mathrm{La}_{2-3 x} \mathrm{Zn}_{1-x} \mathrm{Ru}_{x} \mathrm{O}_{4}$ also crystallizes in $\mathrm{K}_{2} \mathrm{NiF}_{4}$ structure with disordered arrangement of $\mathrm{Zn}^{2+}$ and $\mathrm{Ru}^{5+}$ over the octahedral sites (Kim and Battle 1994). $\mathrm{Sr}_{2} \mathrm{RhO}_{4}$ is reported to be orthorhombic with possible space group Fmmm or Cmca (Shimura et al 1992). The temperature coefficient of resistivity is positive down to $10 \mathrm{~K}$, while magnetic measurements reveal a two-dimensional nature of the magnetic ordering. Another study shows that it crystallizes with the symmetry of space group $14_{1} /$ acd, isostructural with $\mathrm{Sr}_{2} \mathrm{IrO}_{4}$ (Itoh et al 1995).

In $\mathrm{La}_{2} \mathrm{MnO}_{4+\delta}$, the manganese ion is predominantly in $2+$ oxidation state and it is not possible to stabilize this oxidation state in oxides at low temperature. Some workers have reported formation of this phase above $1653 \mathrm{~K}$ and stabilized it by very fast quenching of samples to room temperature (Borlera and Abbattista 1983). In the system $\mathrm{Ca}_{n+1} \mathrm{Mn}_{n} \mathrm{O}_{3 n+1}, \mathrm{Ca}_{2} \mathrm{MnO}_{4}$ is reported to crystallize in tetragonal unit cell in 14 /acd space group (Feltz and Schmalfuss et al 1975; Ganguli 1979; Takahashi and Kamegashira et al 1993). The purity of reaction product is affected by the heating rate. It has been observed that during the preparation of these compounds decomposition of solid-solution precursor does not always directly lead to desired products. For example, appropriate calcite precursors for $n=2$ and 3 phases, when decomposed in oxygen, lead to mixed products which predominantly consist of $\mathrm{CaMnO}_{3}$ and $\mathrm{Ca}_{2} \mathrm{MnO}_{4}$ (Longo and Horowitz 1981). It is preferred that the reactants be introduced in a furnace that has already been pre-heated to the required temperature to get single phase product.
The powder XRD pattern of $\mathrm{La}_{2} \mathrm{PdO}_{4}$ has been indexed on tetragonal unit cell with $a=4.055 \AA$ and $c=12.624 \AA$ in the space group $14 / \mathrm{mmm}$ (Attfield and Ferey 1989). The data suggest that the structure of $\mathrm{La}_{2} \mathrm{PdO}_{4}$ is of $\mathrm{Nd}_{2} \mathrm{CuO}_{4}$-type, rather than the $\mathrm{K}_{2} \mathrm{NiF}_{4}$-type, as the cla ratio is characteristic of the former structure, but too small to be consistent with the latter.

A large number of phases of the system $\operatorname{Ln}_{n} \mathrm{AM}_{n} \mathrm{O}_{3 n+1}$ ( $\mathrm{Ln}=$ rare earth ion, $\mathrm{A}=$ alkaline earth ion and $\mathrm{M}=\mathrm{Co}$, $\mathrm{Ni}, \mathrm{Cr}, \mathrm{Al}, \mathrm{Fe}, \mathrm{Mn}, \mathrm{Ru}, \mathrm{Rh}, \mathrm{Ga}$ ) have been reported in the literature (Blasse 1965, 1968; Joubert et al 1970; Fava et al 1972; Daoudi and Flem 1973; Samaras et al 1973; Demazeau et al 1976a, b, 1979; Benabad et al 1977; Cheruy and Joubert 1981; Sharma and Singh 1995b, 1997). Most of these compounds, showing interesting electric transport and magnetic properties, crystallize either in the tetragonal or orthorhombic crystal symmetry in the space group $14 / \mathrm{mmm}, \mathrm{Fmmm}$ or Cmca. Magnetic studies suggest that $\mathrm{Co}^{3+}$ ions in $\mathrm{LaSrCoO}_{4}$ are present in both high- and low-spin states in equal proportions, while the material undergoes spin state transition above $400 \mathrm{~K}$. Some workers have, however, suggested intermediate spin state for the cobalt ion $\left(t_{2 g}^{5} e_{g}^{\dagger}\right)$ (Rao et al 1988). The iron containing phases are antiferromagnetic insulators. Electrical conduction in $\mathrm{LaSrNiO}_{4}$ occurs via $2 \mathrm{D}$ variable range hopping, while $\mathrm{Ni}^{3+}$ ion is in low spin state. $\mathrm{Ln}_{2} \mathrm{Li}_{0.5} \mathrm{Au}_{0.5} \mathrm{O}_{4}(\mathrm{Ln}=$ rare earth) phases, having trivalent gold in square planar surroundings, also crystallize in tetragonal unit cell (Tresse et al 1993). X-ray diffraction study shows that cla ratio is reduced to great extent $(3.05 \pm 0.06)$ as compared to that of isotropic electronic configuration in $\mathrm{K}_{2} \mathrm{NiF}_{4}$ structure (Glasso 1969). Demazeau et al (1984) have stabilized anisotropic electronic configuration of transition elements (high spin $\mathrm{Fe}^{4+}$, low spin $\mathrm{Co}^{4+}$, medium spin $\mathrm{Co}^{3+}$, low spin $\mathrm{Ni}^{3+}$ and low spin $\mathrm{Cu}^{3+}$ ) from matrix having $\mathrm{K}_{2} \mathrm{NiF}_{4}$ structure, which is the result of the elongation of $\mathrm{MO}_{6}$ octahedra and is confirmed by cla ratio of the tetragonal $\mathrm{K}_{2} \mathrm{NiF}_{4}$-type cell of these phases. John-Teller distortion has also been propounded on this basis. Some other compounds, having $\mathrm{Mn}^{3+}-$ like ions, are also known to undergo John-Teller distortion, which leads to distortion in their structure and properties (Cheruy and Joubert 1981; Sharma and Singh 1995b).

Many manganites having perovskite-related structure such as (La, Sr) $)_{n+1} \mathrm{Mn}_{n} \mathrm{O}_{3 n+1}\left(n=2\right.$ and 3 ) and $\mathrm{Ln}_{1-x} \mathrm{~A}_{x} \mathrm{MnO}_{3}$ $(\mathrm{A}=$ alkaline earth metal ion) exhibit ferromagnetism and insulator-metal transition at low temperature (Mahesh $e t$ al 1996; Sharma and Magotra 1998). These materials also show colossal magnetoresistance (CMR). The $\mathrm{Mn}^{3+} / \mathrm{Mn}^{4+}$ mixed valence state in the manganites creates mobile charge carriers and canting of $\mathrm{Mn}$ spins. These ionic states fluctuate due to electron transfer between them. As a result of this electron transfer, magnetization and metallic conductivity appear almost simultaneously 
(Helmolt et al 1993; Verelst et al 1993; McCormack 1995). A distinct feature of such a barely metallic state in the manganese oxides is that there is a strong exchange interaction between the itinerant $e_{\mathrm{g}}$ electrons (or holes) and the local $t_{2 g}$ spins, which governs the electronic properties including the temperature and magnetic field dependent metal-non-metal phenomenon.

Many layered perovskites of titanium, and niobium and their mixed analogues have been studied recently because of their possible applications in catalysis and electrochemistry (Dion et al 1984; Gopalakrishnan and Bhat 1987; Sato et al 1992; Uma et al 1993; Richard et al 1994). There is growing interest in the proton exchange and subsequent dehydration of the layered alkali oxides. $\mathrm{K}_{2} \mathrm{Nd}_{2} \mathrm{Ti}_{3} \mathrm{O}_{10}$ and $\mathrm{Na}_{2} \mathrm{Nd}_{2} \mathrm{Ti}_{3} \mathrm{O}_{10}$ spontaneously intercalate water, and acid exchange of the compounds leads to formation of the protonated phases. In the mixed niobium and titanium phases, the variation of the Bronsted acidity across the series is probably due to an ordering of niobium-titanium atoms in the perovskite slabs (Gopalakrishnan et al 1993).

In recent years, there are reports of synthesis of some

Table 1. Some important RP-type phases with lattice type/ symmetry.

Compound

Lattice type/symmetry

$\mathrm{RE}_{2} \mathrm{CuO}_{4}(\mathrm{RE}=$ rare earth $)$

$\mathrm{La}_{n+1} \mathrm{Ni}_{n} \mathrm{O}_{3 n+1}(n=1,2,3)$

$\mathrm{La}_{n+1} \mathrm{Co}_{n} \mathrm{O}_{3 n+1}$

$\mathrm{Sr}_{n+1} \mathrm{Ti}_{n} \mathrm{O}_{3 n+1}$

$\mathrm{Sr}_{n+1} \mathrm{Fe}_{n} \mathrm{O}_{3 n+1}$

$\mathrm{Sr}_{n+1} \operatorname{Ir}_{n} \mathrm{O}_{3 n+1}$

$\mathrm{Sr}_{n+1} \mathrm{Cr}_{n} \mathrm{O}_{3 n+1}$

$\mathrm{Sr}_{n+1} \mathrm{~V}_{n} \mathrm{O}_{3 n+1}$

$\mathrm{Sr}_{n+1} \mathrm{Ru}_{n} \mathrm{O}_{3 n+1}(n=1,2)$

$\mathrm{LaSr}_{3} \mathrm{Fe}_{3} \mathrm{O}_{10-\delta}$

$\mathrm{Ca}_{n+1} \mathrm{Mn}_{n} \mathrm{O}_{3 n+1}$

$\mathrm{A}_{2} \mathrm{Ln}_{2} \mathrm{Ti}_{3} \mathrm{O}_{10}(\mathrm{~A}=\mathrm{Na}, \mathrm{K})$

$\mathrm{Sr}_{3} \mathrm{MnM}^{\prime} \mathrm{O}_{7}\left(\mathrm{M}^{\prime}=\mathrm{Ru}, \mathrm{Fe}\right)$

$\left(\mathrm{A}, \mathrm{A}^{\prime}\right)_{n+1} \mathrm{M}_{n} \mathrm{O}_{3 n+1} \quad(n=1,2,3)$

(A, $\mathrm{A}^{n+1}=$ rare earth/alkaline earth

$\mathrm{M}=\mathrm{Cr}, \mathrm{Al}, \mathrm{Ni}, \mathrm{Fe}, \mathrm{Mn}, \mathrm{Ru}, \mathrm{Ga}$ )

$\mathrm{Ln}_{2} \mathrm{Li}_{0.5} \mathrm{Au}_{0.5} \mathrm{O}_{4}$

tetragonal

$\mathrm{La}_{2} \mathrm{PdO}_{4}$

tetragonal

$\mathrm{Sr}_{2} \mathrm{RhO}_{4}$

$14_{1} /$ acd

$\mathrm{Ba}_{2} \mathrm{ZrS}_{4} / \mathrm{Ba}_{2} \mathrm{HfS}_{4}$

$14 / \mathrm{mmm}$

$\mathrm{Ba}_{4} \mathrm{Zr}_{3} \mathrm{~S}_{10}$

Fmmm
RP-type sulphides. $\mathrm{Ba}_{2} \mathrm{ZrS}_{4}$ and $\mathrm{Ba}_{2} \mathrm{HfS}_{4}$ crystallized in the space group $14 / \mathrm{mmm}$ with large unit cell, while $\mathrm{Ba}_{4} \mathrm{Zr}_{3} \mathrm{~S}_{10}$ and $\mathrm{Ba}_{4} \mathrm{Hf}_{3} \mathrm{~S}_{10}$ have orthorhombic cell symmetry; former in the space group $F \mathrm{mmm}$ (Chen and Eichhorn 1991; Saeki et al 1991; Chen et al 1993). Table 1 lists some of the important RP-type phases reported in the literature.

\subsection{Effect of oxygen stoichiometry and doping}

Wide range of oxygen stoichiometry in the RP-type phases, which occurs via completely reversible oxidation-reduction by oxygen gain/loss, is the source of varied change in their structure and properties. It has been shown that oxygen deficiency in RP-phases, when $n=2$, is accounted for by systematic removal of oxygen from the site $(2 \mathrm{a} ; 000)$ linking the $\mathrm{BO}_{6}$ octahedra, while the other oxygen sites remain fully occupied (Dann et al 1992). Structurally, $c$-axis increases with decrease in oxygen content followed by continuous fall in $c$ with further loss of oxygen. $a$ continuously increases with decrease in oxygen stoichiometry. Figure 4 shows variation of cell parameters as function of oxygen content in $\mathrm{Sr}_{3} \mathrm{Fe}_{2} \mathrm{O}_{7-\delta}$. $\mathrm{LaSr}_{3} \mathrm{Fe}_{3} \mathrm{O}_{\mathrm{t} 0-\delta}$ and $\mathrm{La}_{3} \mathrm{Ni}_{2} \mathrm{O}_{7-\delta}$ also systematically follow this trend; the latter undergoing orthorhombic to tetragonal phase transition as $\delta$ changes

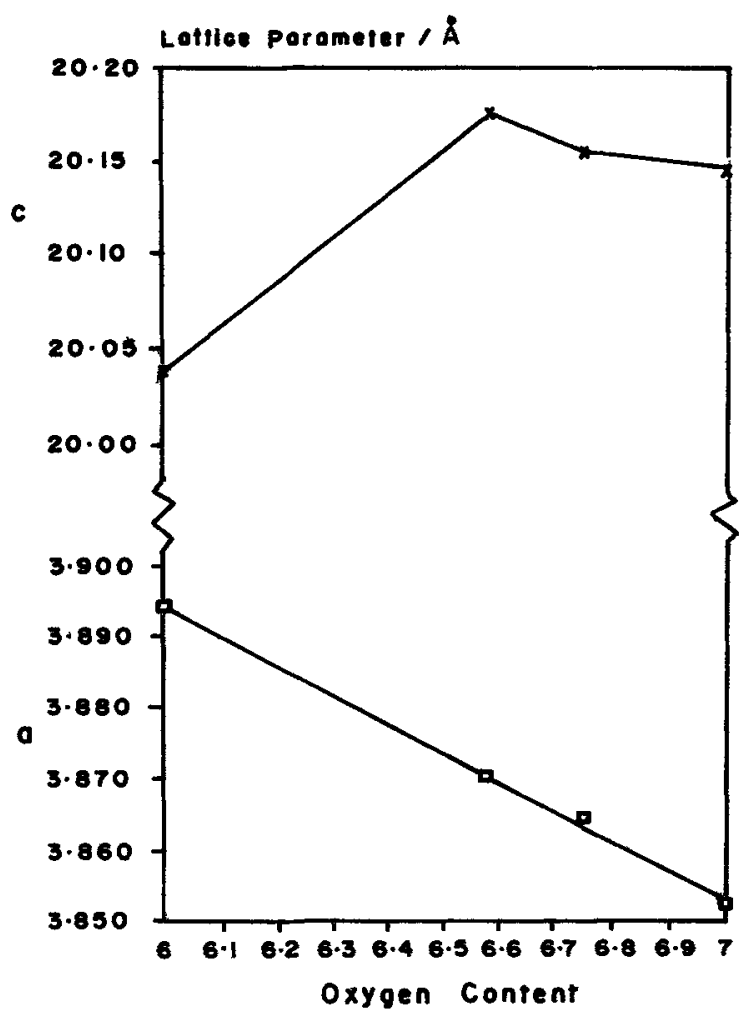

Figure 4. Change of the lattice constants $a$ and $c$ with variation in oxygen content in $\mathrm{Sr}_{3} \mathrm{Fe}_{2} \mathrm{O}_{7-\delta}$. 
from 0.08 to 0.65 (Dann et al 1992; Lees et al 1993; Sreedhar et al 1994). The change in lattice parameters with variation in oxygen content of the system $\mathrm{La}_{3} \mathrm{Ni}_{2} \mathrm{O}_{7-\delta}$ is given in table 2. The complete removal of oxygen in $\mathrm{Sr}_{3} \mathrm{Fe}_{2} \mathrm{O}_{7-\delta}$ produced an unusual squarepyramidal coordination around $\mathrm{Fe}^{3+}$ ion and a stoichiometry of $\mathrm{Sr}_{3} \mathrm{Fe}_{2} \mathrm{O}_{6}$ (Dann et al 1992). The effect of systematic removal of oxygen in $\mathrm{La}_{4} \mathrm{Ni}_{3} \mathrm{O}_{10}$ on the structure and the nature of XRD pattern is shown in figures 5 and 6 . Figure 5 shows removal of $O(2)$ in the first step, which is followed by further loss of oxygen and shift of $\mathrm{O}(4)$ to $(4 \mathrm{~d} ; 0.5 \cdot 25)$ site. The stoichiometric $\mathrm{La}_{4} \mathrm{Ni}_{3} \mathrm{O}_{10}$ is orthorhombic, while $\mathrm{La}_{4} \mathrm{Ni}_{3} \mathrm{O}_{9}$ is tetragonal. Further loss of oxygen leads to shift in the (110) peak with formation of $\mathrm{La}_{4} \mathrm{Ni}_{3} \mathrm{O}_{8}$. The structure of $\mathrm{La}_{4} \mathrm{Ni}_{3} \mathrm{O}_{4}$ could be considered as the triple layer intermediate between $T$ and the so-called infinite-layer structure. Contrary to these observations, the tetragonal $\mathrm{Sr}_{3} \mathrm{CO}_{2} \mathrm{O}_{7-\delta}$ transforms to orthorhombic form in the space group Immm with increase in $\delta$ (Dann and Weller 1995). The ordering of oxygen vacancies in the RP-phase leads to a three-fold tripling along the b-axis. The lattice parameters and change in $\delta$ in the system $\mathrm{Sr}_{3} \mathrm{CO}_{2} \mathrm{O}_{7-\delta}$ are also given in table 2.

Oxidation of insulating $\mathrm{La}_{2} \mathrm{CuO}_{4}$ (i) in oxygen atmosphere under high pressure at elevated temperature to $\mathrm{La}_{2} \mathrm{CuO}_{4+\delta}$ and (ii) by anodic oxidation in aqueous electrolytes at ambient temperatures converts it to superconducting mixed valent state (Beille et al 1987; Cava et al 1987; Mohan Ram et al 1987; Wattaux et al 1990). In the RP-phases, generally, gradual rise in room

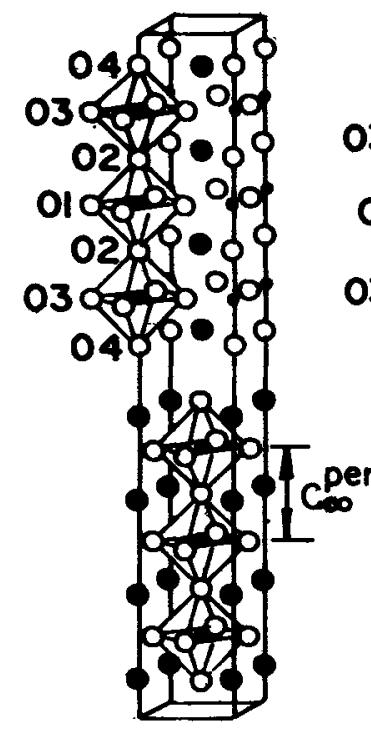

a

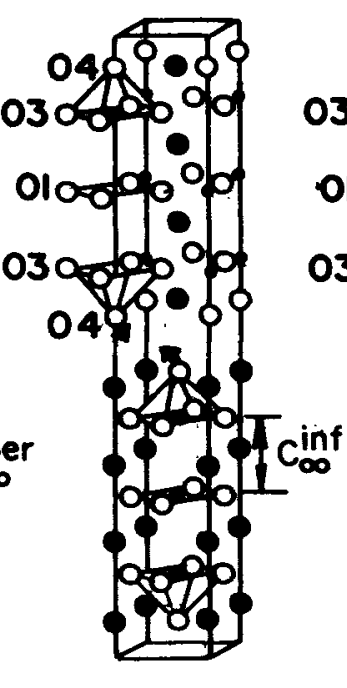

b

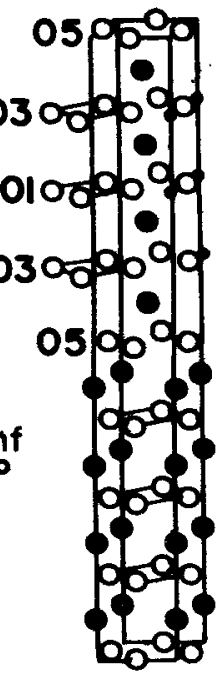

C
Figure 5. Crystal structure of a. $\mathrm{La}_{4} \mathrm{Ni}_{3} \mathrm{O}_{10}$, b. reduced $\mathrm{La}_{4} \mathrm{Ni}_{3} \mathrm{O}_{8}$ as expected and c. as effectively observed. temperature resistivity is observed with decrease in oxygen content. Absolute value of resistivity in $\mathrm{Sr}_{2} \mathrm{FeO}_{4}$ was three orders of magnitude large for the oxygen deficient sample than that of the one containing more oxygen (Adler 1994). Metallic $\mathrm{La}_{3} \mathrm{Ni}_{2} \mathrm{O}_{7}$ transforms on reduction to insulating $\mathrm{La}_{3} \mathrm{Ni}_{2} \mathrm{O}_{6.92}$ and $\mathrm{La}_{3} \mathrm{Ni}_{2} \mathrm{O}_{6.33}$ (Sreedhar et al 1994). With an increase in $\delta$ in $\mathrm{Sr}_{4} \mathrm{~V}_{3} \mathrm{O}_{10-\infty}$, the carrier concentration decreases and electrical conduction changes from metallic to semiconducting, the effective magnetic moment increases and the material transforms from polyparamagnetic to normal paramagnetic (Rey et al 1990; Gong et al 1991). The localization of carriers could be explained by the mobility edge formed by the random potential of $\mathrm{V}^{3+}$ ions and/or oxygen deficiencies. However, contrary to the general behaviour, the room temperature resistivity of the phases of the family $\mathrm{Ca}_{n+1} \mathrm{Ti}_{n} \mathrm{O}_{3 n+1-\delta}$, decreases with increase in $\delta$ resulting in decreased characteristic energy of hopping (B). When the characteristic energy (B) becomes zero, the metallic $\mathrm{Ca}_{3} \mathrm{Ti}_{2} \mathrm{O}_{7-\delta}$ and $\mathrm{Ca}_{4} \mathrm{Ti}_{3} \mathrm{O}_{10-\delta}$ are stabilized at all temperatures. In $\mathrm{Pr}_{2} \mathrm{NiO}_{4+\delta}$ and $\mathrm{Nd}_{2} \mathrm{NiO}_{4+\delta}$ evidence of long-range magnetic order is observed as $\delta$ becomes small (Buttrey and Honig 1988).

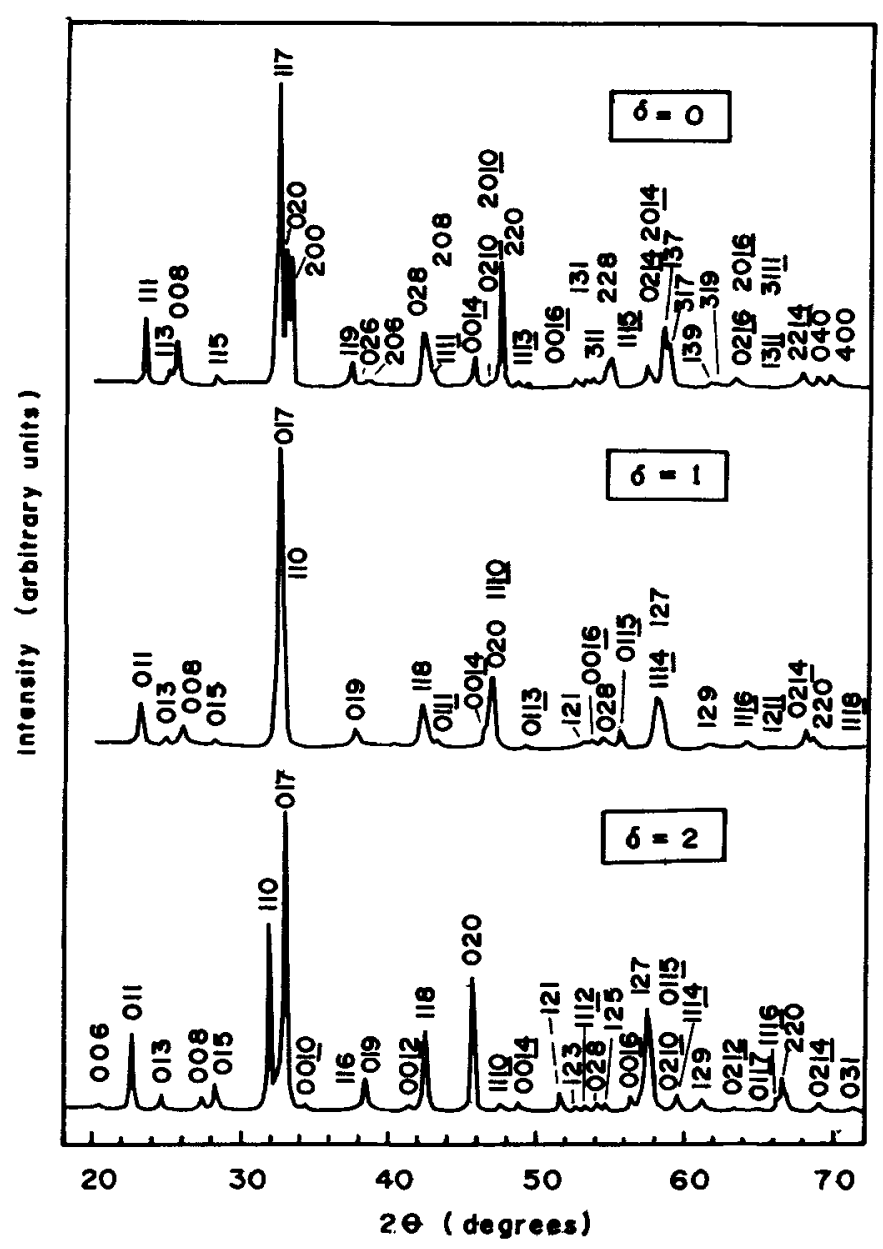

Figure 6. XRD patterns of $\mathrm{La}_{4} \mathrm{Ni}_{3} \mathrm{O}_{10-\delta}(\delta=0,1,2)$. 
Doping at A site by a suitable ion is one of the tools which could induce tremendous variation in the behaviour of the RP phases. The insulating $\mathrm{La}_{2} \mathrm{CuO}_{4}$ becomes superconducting when lanthanum is partially replaced by bivalent alkaline earth ion or basic monovalent cation with appropriate ionic size. Enthalpy of formation of $\mathrm{La}_{2-x} \mathrm{~A}_{x} \mathrm{CuO}_{4}(\mathrm{~A}=\mathrm{Ba}, \mathrm{Sr}, \mathrm{Ca}$ and $\mathrm{Pb})$ suggests that more basic A-site cations tend to energetically stabilize higher oxidation states of B-site cations, the phenomenon responsible for pronounced change in the electrical properties in the parent phase (Dicarlo et al 1992). $\mathrm{La}_{2-x} \mathrm{Sr}_{x} \mathrm{NiO}_{4}$ offers another interesting example describing change in properties as a function of doping at A-site (figure 7). The material behaves like an AF-insulator for $x$ up to 0.1 . When $x$ lies between $0 \cdot 1$ and 0.95 , it is non-metal showing variable range hopping mechanism for electrical conduction at low temperature and exponentially activated conduction at comparatively higher temperatures, while it turns to metallic form for concentration of $x$ between 1.0 and 1.3. The resistivity data for the last phase in the temperature range up to $25 \mathrm{~K}$ follow $T^{1 / 2}$ dependence, where strong electron-electron interactions occur in the presence of disorder in a diffusive metallic phase (Sreedhar and Honig 1994). Orthorhombic $\mathrm{Nd}_{2} \mathrm{NiO}_{4+\delta}$ undergoes a phase transition to pseudo-tetragonal symmetry upon doping with $\mathrm{Sr}^{2+}$ at $\mathrm{Nd}$-site (Arbuckle et al 1990). The increased magnetic moment in the system $\mathrm{Nd}_{2-x} \mathrm{Sr}_{x} \mathrm{NiO}_{4}$ with increase in $x$ is attributed to the frustration of $\mathrm{AF}$ pairing that originates from the mixed valence of $\mathrm{Ni}^{2+} / \mathrm{Ni}^{3+}$, while it showed a metal-semiconductor transition which is related to the onset of a charge density wave characteristic of half-filled conduction bands (Takeda et al 1992).

Both antiferromagnetic and ferromagnetic interactions are present in $\mathrm{LaSr}_{3} \mathrm{Fe}_{3} \mathrm{O}_{10-\varsigma}$, the former predominates for large value of $\delta$, while the latter when $\delta$ is small (Kim et al 1992). In $\mathrm{Sr}_{3} \mathrm{Fe}_{2} \mathrm{O}_{6 \cdot 1}$, which is antiferromagnetic at room temperature, increasing the oxygen content and hence $\mathrm{Fe}^{4+}$ level results in rapid decrease in $T_{\mathrm{c}}$ approaching $0 \mathrm{~K}$ for $\mathrm{Sr}_{3} \mathrm{Fe}_{2} \mathrm{O}_{6.5}$. Further increase in oxygen content reverses the trend when $T_{\mathrm{c}} \sim 130 \mathrm{~K}$ is found for

Table 2. Variation of lattice parameters with change in oxygen content.

\begin{tabular}{lll}
\hline Phase & Space group & \multicolumn{1}{c}{ Lattice parameters } \\
\hline $\mathrm{La}_{3} \mathrm{Ni}_{2} \mathrm{O}_{7 .(x)}$ & Fmmm & $a=5.396 ; b=5.449 ; c=20.516 \AA$ \\
$\mathrm{La}_{3} \mathrm{Ni}_{2} \mathrm{O}_{6.35}$ & $I 4 / \mathrm{mmm}$ & $a=3.8757 ; c=20.062 \AA$ \\
$\mathrm{Sr}_{3} \mathrm{CO}_{2} \mathrm{O}_{6.06}$ & $I 4 / \mathrm{mmm}$ & $a=3.8231 ; c=20.0826 \AA$ \\
$\mathrm{Sr}_{3} \mathrm{CO}_{2} \mathrm{O}_{5.94}$ & $I m m m$ & $a=3.8379 ; b=11.4898 ;$ \\
$\mathrm{Sr}_{3} \mathrm{CO}_{2} \mathrm{O}_{5.78}$ & $I m m m$ & $c=20.0812 \AA$ \\
& & $a=3.8631 ; b=11.4319 ;$ \\
\end{tabular}

$\mathrm{Sr}_{3} \mathrm{Fe}_{2} \mathrm{O}_{6 \cdot 90^{*}}$. The phenomenon is attributed to a weak ferromagnetic $\mathrm{Fe}^{4+}-\mathrm{O}^{2-}-\mathrm{Fe}^{4+}$ exchange interaction and a strong $\mathrm{Fe}^{3+}-\mathrm{O}^{2-}-\mathrm{Fe}^{3+}$ interaction (Dann et al 1992). In $\mathrm{Sr}_{3 x} \mathrm{La}_{2-3 x} \mathrm{Zn}_{1-x} \mathrm{Ru}_{x} \mathrm{O}_{4}$, as the ruthenium concentration increases, short-range antiferromagnetic interactions between $\mathrm{Ru}^{5+}$ ions become more important (Kim and Battle 1994).

\subsection{Preparative strategies}

The ceramic method of preparation has been widely used for the preparation of these compounds. Appropriate atmosphere needs to be maintained during the course of synthesis to attain proper stoichiometry. Usually dry and oxygen free argon or nitrogen is used for creating an inert atmosphere, while hydrogen or a combination of hydrogen and some inert gas is needed for creating a reducing atmosphere. Occasionally evacuated silica ampules have also been used towards this end. If the required oxygen concentration is high, the atmosphere may be controlled by carefully maintaining the high oxygen pressure, while for low concentration of oxygen buffering mixtures such as $\mathrm{CO} / \mathrm{CO}_{2}$ or $\mathrm{H}_{2} / \mathrm{H}_{2} \mathrm{O}$ are employed. Annealing of an oxide sample at low temperature under ordinary pressures of oxygen, leads to increased oxygen stoichiometry (Dann et al 1992; Zhang and Greenblatt 1994; Zhang et al 1994), while electrochemical oxidation procedure has also been used to control and extend oxygen stoichiometry of these phases (Demourgues et al 1993). In order to retain the high temperature structure, samples are some times quenched to various host-medium such as liquid nitrogen, water, water-methyl alcohol-ice or air, depending on the nature of the samples (Janecek and Wirtz 1978; Borlera and Abbattista 1983; Lees et al 1993).

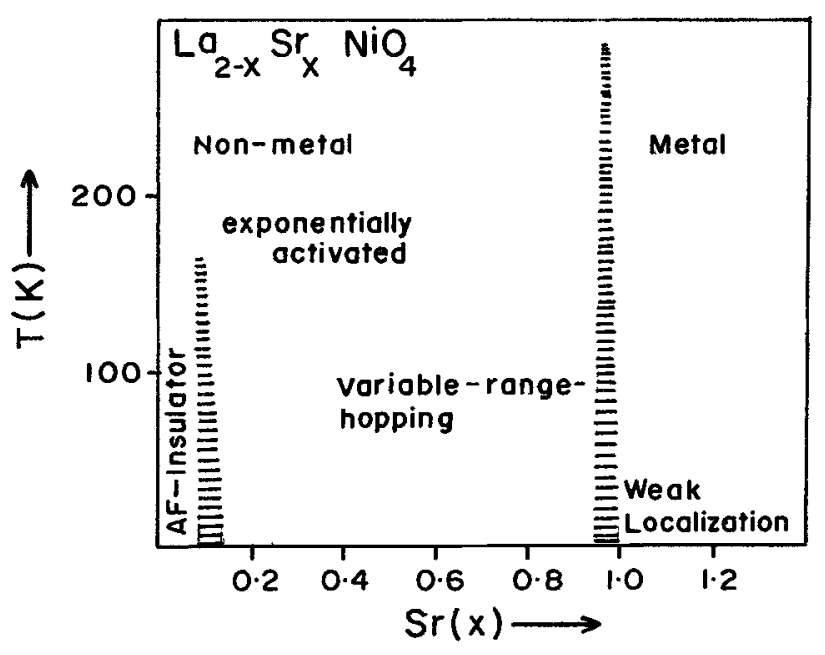

Figure 7. Schematic diagram describing changes in the electric transport as function of $\mathrm{Sr}$ doping in $\mathrm{La}_{2-x} \mathrm{Sr}_{x} \mathrm{NiO}_{4}$. 
Since large diffusional distances of the order 10,000 unit cells are involved in a solid-state reaction, drastic conditions of temperature are required to overcome the diffusional limitations to get a single desired phase and still it may not be possible to achieve this in many cases. Application of high temperature in the ceramic technique to overcome diffusional limitations leads to the crystalline products of low surface area and limits the ability to stabilize the higher valence states of transition metal elements.

Ideally, in order to achieve complete reaction in shortest time span and at lowest possible temperature, one would have to achieve mixing of component cations on an atomic scale and a compound precursor is required. However, one of the limitations of this method is that it is not always possible to prepare a precursor compound with the desired composition. This limitation of a compound precursor could be overcome by preparation of solid solution precursors (Longo and Horowitz 1981). A solid-solution is the interpenetration on an atomic scale of two chemically different but structurally similar lattices. The method involves preparation of isostructural compounds of the component cations with a common ion such as oxalate, nitrate, hydroxide or cyanide, so that they form a solid-solution between two or more cations in the proper ratios. A complex oxide can be formed at low temperature by modification of the solid-solution. In a solid-solution precursor system, cations are already mixed on an atomic scale in a single phase precursor so that decomposition or reduction is rapid and complete at significantly low temperatures and shorter time; and the nature of solid-solution is such that it is possible to continuously vary the cation composition in the structure and one is not limited to discrete compound precursor.

\subsection{Characterization}

Oxygen content generally determines the crystal symmetry and physical properties of these compounds and, therefore, its estimation is important. Iodometry is the most common method used for the estimation of oxygen content. Details of this method are available in the literature on analytical chemistry. Atomic absorption spectrometry, energy dispersive $\mathrm{X}$-ray analysis and thermal gravimetric analysis are some of the other important techniques used for the purpose. Heating of a sample in continuous flow of either hydrogen or a mixture of $\mathrm{H}_{2} / \mathrm{Ar}$ leads to its reduction to transition metal and alkaline earth/rare earth oxides, depending upon the species present in the sample. The study could lead to estimation of oxygen content (Lacorre 1992; Zhang and Greenblatt 1994; Zhang et al 1994).

Neutron and X-ray powder diffractometry are normally powerful and commonly used methods for crystal structure determination; the former being additionally successful for precise magnetic structure elucidation, especially in complex cases with multimagnetic sub-lattices. Rietveld profile analysis helps in precise determination of crystal structure in polycrystalline materials. Frequent coexistence of several members of homologous series and the presence of structural disorder and microdomains of different structures in individual crystals make the powder patterns complex and diffuse and difficult to interpret in detail. X-ray single crystal structural analysis is an

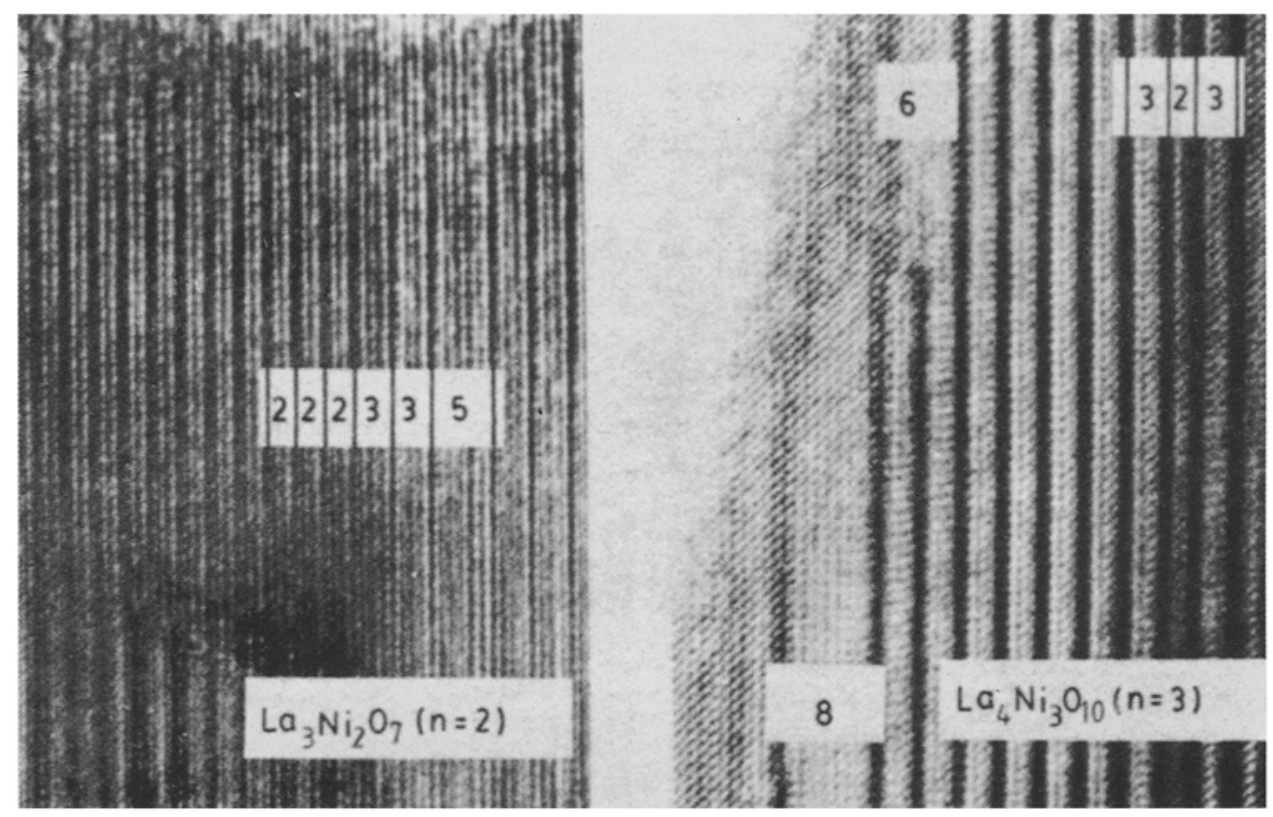

Figure 8. Lattice images of $\mathrm{La}_{3} \mathrm{Ni}_{2} \mathrm{O}_{7}$ and $\mathrm{La}_{4} \mathrm{Ni}_{3} \mathrm{O}_{10}$ showing the presence of other members of $\mathrm{La}_{n+1} \mathrm{Ni}_{n} \mathrm{O}_{3 n+1}$ series (from Rao 1985). 
appropriate technique for identification of phases when good single crystals are available. This method is unsurpassed for getting precise structural information, but only average description of the atomic arrangement is obtained. Although the presence of disorder and defects can usually be detected when present frequently, study of intergrowth in RP-phases is rarely possible.

Transmission electron microscopy combined with selected area electron diffraction has proved to be the best technique for identification of phases of complex structure in inhomogeneous samples. HREM has unique advantage for the direct real-space study of interfaces. By direct lattice imaging, high resolution electron microscopy can be used to reveal inter-growth in RP-type phases. In these compounds, these studies show coexistence of lamellae with different $n$-values. Instead of ordered intergrowth of neighbouring members, disordered intergrowth of different members occurs, typical of them being $\mathrm{Sr}-\mathrm{Ti}-\mathrm{O}$ and $\mathrm{La}-\mathrm{Ni}-\mathrm{O}$ systems (Tilley 1977; Rao 1985; Rao and Thomas 1985). Figure 8 shows intergrowth of different phases in $\mathrm{La}_{n+1} \mathrm{Ni}_{n} \mathrm{O}_{3 n+1}$ family (Rao 1985).

\section{Conclusions}

Study of RP-type phases offers potential for synthesis and identification of phases which could be of theoretical and practical use in science and technology such as room temperature superconductors, ideal semiconductors, magnetic materials and materials with applications like catalysts, ferroelectrics, dielectrics, piezoelectrics, electrode material for batteries, fuel cells and so on. Every day there are continuous new reports of developments in this area. It is certain that some of the intergrowth structures have novel properties, thus intergrowth could be used as a tool for fashioning materials with desired properties in RP phases. As far as synthesis is concerned, quenching at rapid pace from very high to room temperature could lead to stabilization of materials with lower oxidation states and unique properties. 'Chemie douce' methods could prove ideal for development of materials with high surface area. When $r_{\mathrm{A}} / r_{\mathrm{B}}$ ratios are not ideal for stabilizing structure of RP-type phases under normal conditions, high pressure techniques could lead to synthesis of novel phases. There are numerous oxides which absorb microwave energy and the strong absorption is reflected in heating effects when few grams of these samples could attain high temperatures within a minute or so. This property could be exploited to develop convenient and high yield synthesis of such solid-state materials (Baghurst and Mingos 1988). Doping at the cation sites and variation of oxygen stoichiometry could be ideal tools to cause novel changes in electric transport and magnetic properties in these materials.

\section{Acknowledgement}

Thanks are due to DST, New Delhi for financial support. IBS is thankful to Prof. C N R Rao, FRS for encouragement.

\section{References}

Adler P 1994 J. Solid State Chem. 108275

Arbuckle R W, Ramanujachary K V, Zhang Z and Greenblatt M 1990 J. Solid State Chem. 88278

Attfield J P and Ferey G 1989 J. Solid State Chem. 80286

Baghurst D R and Mingos D M P $1988 \mathrm{~J}$. Chem. Soc., Chem. Commun. 829

Bassat J M, Odier P and Gearvias F 1987 Phys. Rev. B35 7126

Bednorz J G and Muller K A 1986 Z. Phys. B-Condensed Matter 64189

Beille J et al 1987 Physica B146 307

Benabad A, Daoudi A, Salmon R and Flem G L 1977 J. Solid State Chem. 22121

Blasse G 1965 J. Inorg. Nucl. Chem. 272683

Blasse G $1968 \mathrm{~J}$. Inorg. Nucl. Chem. 30656

Borlera M L and Abbattista F 1983 J. Less-Common Metals 92 55

Bouloux J C, Soubeyroux J L, Flem G L and Hagenmuller P 1981 J. Solid State Chem. 3834

Bringley J F, Trail S S and Scott B A 1990 J. Solid State Chem. 86310

Buttrey D J and Honig J M 1988 J. Solid State Chem. 7238

Buttrey D J, Honig J M and Rao C N R 1986 Mater. Res. Bull. 64287

Cava J, Van Dover R B, Batlogg B and Rietmann E A 1987 Phys. Rev. Lett. 58408

Cava R J et al 1995 J. Solid State Chem. 1161141

Chen B H 1996 J. Solid State Chem. 12563

Chen B H and Eichhorn B W 1991 Mater. Res. Bull. 261035

Chen B H and Eichhorn B W 1992 J. Solid State Chem. 97 340

Chen B H, Wong W and Eichhorn B W 1993 J. Solid State Chem. 10375

Cheruy M N D and Joubert J C 1981 J. Solid State Chem. 40 14

Cryot M et al 1990 J. Solid State Chem. 85321

Dann S E and Weller M T 1995 J. Solid State Chem. 115499

Dann S E, Weller M T and Currie D B 1992 J. Solid State Chem. 97179

Daoudi A and Flem G L 1973 Mater. Res. Bull. 81103

Demazeau G, Courbin P, Main I G and Flem G L 1976a C.R. Acad. Sci. Paris 28361

Demazeau G, Pouchard M and Hagenmuller P 1976b J. Solid State Chem. 18159

Demazeau G, Courbin P, Flem G L, Pouchard M, Hagenmuller P, Soubeyroux J L, Main I G and Robins G A 1979 Nouv. J. Chem. 3171

Demazeau G, Buffat B, Pouchard M and Hagenmuller P 1984 J. Solid State Chem. 54389

Demourgues A, Wattiaux A, Grenier J C, Pouchard M, Soubeyroux J L, Dance J M and Hagenmuller P 1993 J. Solid State Chem. 105458 
Dicarlo J, Bularzik J and Navrotsky A 1992 J. Solid State Chem. 96 381

Dion M, Ganne M, Toumoux M and Ravez J 1984 Ress. Chim. Mineral 2192

Drenan J, Tavares C P and Steele B C H 1982 Mater. Res. Bull. 17621

Fava J, Ondalov $Y$, Reau J M, Flem $G$ L and Hagenmuller $P$ 1972 C. R. Acad. Sci. Paris 2741837

Feltz A and Schmalfuss S 1975 Z. Chem. 15289

Flem G L, Demazeau G and Hagenmuller P 1982 J. Solid State Chem. 4482

Ganguli D 1979 J. Solid State Chem. 30353

Ganguly P and Rao C N R 1984 J. Solid State Chem. 53193

Geller S and Wood E A 1956 Acta Crytallogr. 9563

Glasso F S 1969 Structure, properties and preparation of perovskite-type compounds (Oxford: Pergamon Press) p. 4

Gong W, Xue J S and Greedan J E 1991 J. Solid State Chem. 91180

Goodenough J B 1971 Progress in solid state chemistry (ed) H Reiss (Oxford: University Press) p. 145

Gopalakrishnan J and Bhat V 1987 Inorg. Chem. 264299

Gopalakrishnan J, Uma S and Bhat V 1993 Chem. Mater. 5 132

Greedan J E, Liu G, Arbuckle B W, Ramanujachary K V and Greenblatt M 1992 J. Solid State Chem. 97419

Gunther W and Schollhorn R 1992 Physica C203 115

Helmolt R V, Wecker J, Hotzapfel B, Schultz L and Samwer K 1993 Phys. Rev. Lett. 712391

Huang Q, Soubeyroux J L, Chmaissem O, Sora I N. Santoro A, Cava R J, Krajewski J J and Peck Jr. W F 1994 J. Solid State Chem. 112355

Itoh M, Shikano M, Liang R, Kawaji H and Nakamura T 1990 J. Solid State Chem. 88597

Itoh M, Shimura T, Inaguma Y and Morii Y $1995 \mathrm{~J}$. Solid State Chem. 118206

James A C W P, Zahurak S H and Murphy D W 1989 Nature (London) 338240

Janecek J J and Wirtz G P 1978 J. Am. Ceram. Soc. 61242

Joubert J C, Collomb A, Elmaleh D, Flem G L, Daoudi A and Ollivier G $1970 \mathrm{~J}$. Solid State Chem. 2343

Kafalas J A and Longo J M 1972 J. Solid State Chem. 455

Kakol Z, Spalek J and Honig J M 1989 J. Solid State Chem. 79288

Katz L and Ward R 1964 Inorg. Chem. 3205

Kim I, Itoh M and Nakamura T 1992 J. Solid State Chem. 101 77

Kim S H and Battle P D 1994 J. Solid State Chem. 112262

Kniga M V, Vygovskii I I and Klementoviah E E 1979 Russian J. Inorg. Chem. 24652

Lacorre P 1992 J. Solid State Chem. 97495

Lees J Y, Swinnea J S, Steinfink H, Reiff W M, Pei S and Jorgensen J D 1993 J. Solid State Chem. 1031

Lehmann U and Buschbaum H M 1980 Z. Anorg Allg. Chem. 47059

Lehuede P and Daire M 1973 C. R. Acad. Sci. Paris 2761783

Lichtenberg F, Catana A. Mannhart J and Schlom D G 1992 Appl. Phys. Lett. 601138

Longo J M and Horowitz 1981 in Preparation and characterization of materials (eds) J M Honig and C N R Rao (New York: Academic Press) p. 29
Longo J M and McCauley R A 1986 J. Am. Ceram. Soc. 69 699

Maeno $Y$, Hashimoto $H$, Yoshida $K$, Nishizaki $S$, Fujita $T$, Bednorz J G and Lichtenberg F 1994 Nature 372532

Mahesh R, Mahendiran R, Raychaudhuri A K and Rao C N R $1996 \mathrm{~J}$. Solid State Chem. 122448

Manthiram A and Goodenough J B $1990 \mathrm{~J}$. Solid State Chem. 87402

McCormack M, Jin S, Tiefel T H, Fleming $\mathrm{R} M$ and Philips J M 1994 Appl. Phys. Lett. 643045

Mohan Ram R A, Ganapathi L, Ganguly P and Rao C N R 1986 J. Solid State Chem. 63139

Mohan Ram R A, Ganguly P and Rao C N R 1987 Phase Trans. 10107

Muller-Buschbaum H K and Wilkens J 1990 Z. Anorg. Allg. Chem. 591161

Nanjundaswamy K S, Lewicki A, Kakol Z, Gopalan P, Metcalf P. Honig J M, Rao C N R and Spalek J 1990 Physica C166 361

Ohashi N, Teramoto $\mathrm{Y} Y$, lkawa $\mathrm{H}$, Fukunaga $\mathrm{O}$ and Tanaka J 1992 J. Solid State Chem. 97434

Poix P 1980 J. Solid State Chem. 3195

Rao C N R 1985 Bull. Mater. Sci. 7155

Rao C N R and Thomas J M 1985 Acc. Chem. Res. 18113

Rao C N R and Gopalakrishnan J 1986 New directions in solid state chemistry (Cambridge: University Press) p. 30

Rao C N R, Buttrey D J, Otsuka N, Ganguly P, Harrison H R, Sandberg C J and Honig J M 1984 J. Solid State Chem. 51 266

Rao C N R, Ganguly P. Singh K K and Mohan Ram R A 1988 J. Solid State Chem. 7214

Rao C N R, Ganguli A K and Nagarajan R 1989 Pramana-J. Phys. $32 \mathrm{~L} 177$

Rey M J, Dehandt P, Joubert J C, Andron B L. Cryot M and Lackmann F C 1990 J. Solid State Chem. 86101

Richard M, Brohan L and Tournnoux M 1994 J. Solid State Chem. 112345

Ruddlesden S N and Popper P 1957 Acta Crystallogr. 10538

Ruddlesden S N and Popper P 1958 Acta Crystallogr. 1154

Saeki M, Yojima Y and Onoda M 1991 J. Solid State Chem. 92286

Samaras D, Collomb A and Joubert J C 1973 J. Solid State Chem. 7337

Sato M, Abo J, Jin T and Ohta M 1992 Solid State Ionics 5185

Seppanen M and Tikkannen M H 1976 Acta Chem. Scand. A30 389

Sharma I B and Singh D 1995a Indian J. Chem. A34 630

Sharma I B and Singh D 1995b Proc. Indian Acad. Sci., Chem. Sci. 107189

Sharma I B and Singh D 1996 Proc. Indian Acad. Sci., Chem. Sci. 108415

Sharma I B and Singh D 1997 Indian J. Chem. A36 80

Sharma I B and Magotra S K $1998 \mathrm{~J}$. Alloys \& Compounds (in press)

Sharma I B, Singh D and Magotra S K 1998 J. Alloys \& Compounds 26913

Shimura T, Itoh M and Nakamura T 1992 J. Solid State Chem. 98198

Singh K K, Ganguly P and Goodenough J B 1984 J. Solid State Chem. 52254 
Soubeyroux J L, Courbin P, Foumers L, Fruchart D and Flem G L 1980 J. Solid State Chem. 31313

Sreedhar K and Honig J M 1994 J. Solid State Chem. 111147 Sreedhar K, McElfresh M, Perry D, Kim D, Metcalf P and Honig J M 1994 J. Solid State Chem. 110208

Suzuki N, Noritake T, Yamamoto N and Hioki T 1991 Mater. Res. Bull. 261

Takahashi J and Kamegashira N 1993 Mater. Res. Bull. 28565

Takeda Y, Nishijima M, Imanishi N, Kanno R, Yamamoto O and Takano M 1992 J. Solid State Chem. 9672

Takeno S, Nakamura S, Nomaki T, Fukushima $\mathrm{N}$ and Ando $\mathrm{K}$ 1991 J. Solid State Chem. 94432

Tilley R J D 1977 J. Solid State Chem. 21293

Tokura Y, Takagi H and Uchida S 1989 Nature (London) 387 345
Tresse F, Demazeau G, Sanchez J P, Fournes L and Suh K S 1993 J. Solid State Chem. 10395

Uma S, Raju A R and Gopalakrishnan J 1993 J. Mater. Chern. 3709

Verelst M, Rangavittal N, Rao C N R and Rousset A 1993 J. Solid State Chem. 10474

Wattaux A, Park J C, Grenier J C and Pouchard M 1990 C. R. Acad. Sci. Paris 3101047

Wells A F 1978 Structural inorganic chemistry (Oxford: University Press) p. 498

Williams T, Lichtenberg F, Reller A and Bednorz G 1991 Mater. Res. Bull. 26763

Zhang Z and Greenblatt M 1994 J. Solid State Chem. 111141

Zhang Z, Greenblatt M and Goodenough J B $1994 \mathrm{~J}$. Solid State Chem. 108402 